\title{
A rare case report of cornual pregnancy
}

\section{Priyanka Bansal*, Gargi Aggarwal, Isha Bansal}

Department of Obstetrics and Gynecology, Kalpana Chawla Government Medical College, Karnal, Haryana, India

Received: 21 August 2021

Accepted: 14 September 2021

\author{
*Correspondence: \\ Dr. Priyanka Bansal, \\ E-mail: pribns126nov@gmail.com
}

Copyright: (C) the author(s), publisher and licensee Medip Academy. This is an open-access article distributed under the terms of the Creative Commons Attribution Non-Commercial License, which permits unrestricted non-commercial use, distribution, and reproduction in any medium, provided the original work is properly cited.

\begin{abstract}
Cornual pregnancy is a rare type of ectopic pregnancy in which embryo implants in the junction between the fallopian tube and uterus. Ectopic pregnancy is more common in the ampullary region of the fallopian tube. However, cornual (interstitial) pregnancy is seen in $2-4 \%$ of ectopic pregnancies. It is more dangerous than other ectopic as it may lead to catastrophic hemorrhage, shock with mortality rate of $2-2.5 \%$. A cornual pregnancy is diagnosed at $7+3$ week of amenorrhea in 27-year-old healthy woman. Ultrasound examination showed a right live cornual pregnancy with CRL corresponding to $6+4$ week of gestation with fetal heart pulsation. We performed right cornuostomy by laparotomy without any immediate or delayed postoperative complications. Cornual pregnancy poses significant diagnostic and therapeutic challenge; early diagnosis may help to select the proper management and treatment according to the clinical presentation, hemodynamic stability, serum b-hCG level and ultrasound findings. Early diagnosis and management remain the mainstay for tackling maternal mortality due to cornual pregnancy.
\end{abstract}

Keywords: Cornual pregnancy, Ectopic pregnancy, Ultrasound, B-hCG, Cornuostomy

\section{INTRODUCTION}

Cornual pregnancy is a rare type of ectopic pregnancy in which embryo implants in the junction between the fallopian tube and uterus. ${ }^{1,2}$ Ectopic pregnancy is more common in the ampullary region of the fallopian tube. However, cornual (interstitial) pregnancy which is seen in about $2-4 \%$ of ectopic pregnancies. ${ }^{3}$ It is more dangerous than other ectopic as it may lead to catastrophic hemorrhage, shock, uterine rupture with mortality rate of $2-2.5 \% .^{3}$ Although many surgeons have attempted to differentiate interstitial from cornual pregnancy, but these are difficult to separate anatomically and are classified together. ${ }^{4}$ The risk factors for interstitial pregnancy do not differ from those for classical tubal pregnancy. Pathogenetically, the most important risk factor is impaired tubal function. All the conditions leading to impaired tubal function, namely chronic pelvic inflammation, endometriosis or tubal surgery leads to an increased risk of ectopic pregnancy. ${ }^{5}$

\section{CASE REPORT}

A 27-year-old G4A3 presented at $7+3$ weeks of amenorrhea with complaint of lower abdominal pain and spotting per vaginum for 3 days. She was hemodynamically stable with $\mathrm{BP}=120 / 80 \mathrm{mmHg}, \mathrm{PR}=104$ bpm. The lower abdomen is soft, non-tender; on per vaginal examination uterus was bulky with tender mass on right side of fundus and mild cervical motion tenderness was present. Her urine pregnancy test was positive. A blood sample for hemoglobin and b-hCG was taken at admission, while transabdominal scan revealed right live cornual pregnancy, with CRL corresponding to $6+4$ weeks of gestation with fetal heart rate of $150 \mathrm{bpm}$. Her serum bhCG at access was $50,532 \mathrm{mIU} / \mathrm{ml}$. Patient was taken for emergency laparotomy after informed and written consent.

Intraoperative findings were: uterus was bulky, right cornual pregnancy of $\sim 4 \times 3 \mathrm{~cm}$ size with impending rupture; left tube, right and left ovaries were normal. 
Patient was very apprehensive regarding her future fertility as she didn't have any live issue so we performed right cornuostomy with evacuation of products as cornuostomy is considered to cause less tubal damage than cornual resection and may have better pregnancy outcomes. Postoperatively patient was stable, her serum b-hCG on fourth postoperative day was $1377 \mathrm{mIU} / \mathrm{ml}$, and discharged on fifth postoperative day without any complication. She was given a follow up appointment a week later and was advised for caesrean section in subsequent pregnancy to reduce the risk of uterine rupture. The histopathology report was right cornual pregnancy. Her b-hCG was progressively decreased and came to normal limit within 6 weeks.

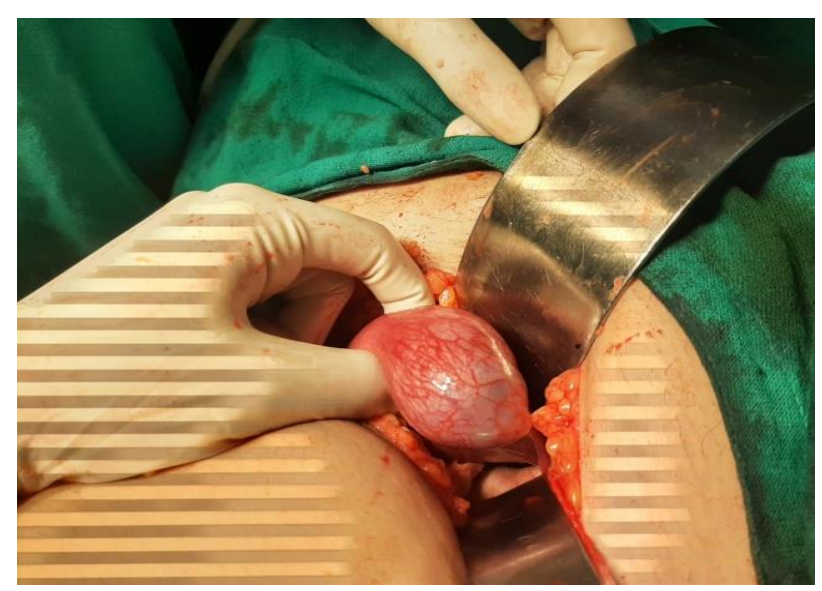

Figure 1: Right cornual pregnancy.

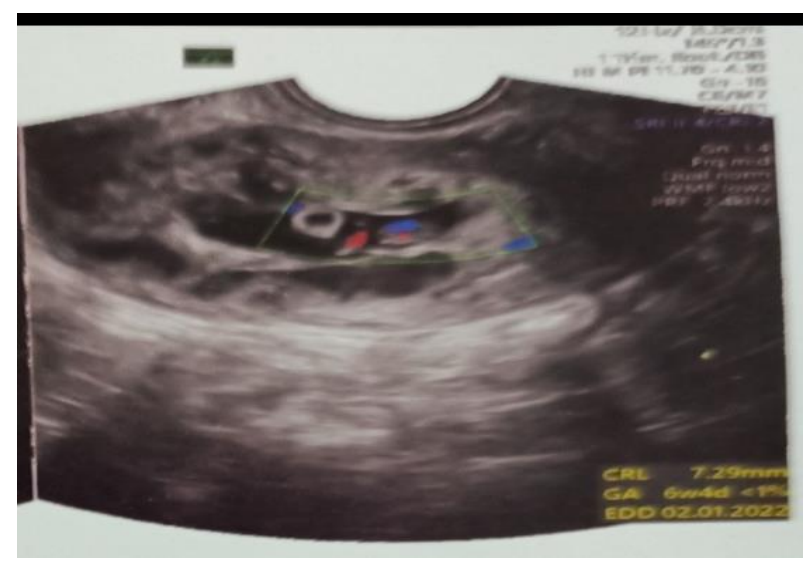

Figure 2: Transvaginal ultrasound showing right cornual pregnancy.

\section{DISCUSSION}

Cornual pregnancy is a rare form of ectopic pregnancy but has catastrophic presentation when diagnosis is missed. it is important to diagnose cornual pregnancy before it ruptures. The morbidity and mortality are directly related to the length of time before diagnosis. A cornual pregnancy may appear as an intrauterine eccentric pregnancy on ultrasound. Also, as the myometrium can distend to accommodate the pregnancy, these cases are usually diagnosed late. Diagnosis is made by transabdominal or transvaginal ultrasonography. ${ }^{6}$

Ultrasound criteria for making the diagnosis includes: Absence of gestational sac in uterine cavity, gestational sac seen independently and less than $1 \mathrm{~cm}$ from the lateral edge of the uterine cavity, thin layer of myometrium around gestational sac (Paucity of myometrium around myometrium) and Interstitial line sign (echogenic line extending to the gestational sac): During early cornual gestation, the sac is located in the lateral part of uterus. Later on, the gestational sac may be located above the uterine fundus. Thus, cornual pregnancy detected late may appear as an eccentric uterine pregnancy. ${ }^{7}$ Doppler Ultrasound can help in diagnosis by showing increase vasculature around gestational sac (ring of fire).

Common symptoms of cornual pregnancy are abdominal pain and vaginal bleeding, while signs of acute abdomen may occur in case of rupture and hemoperitoneum.

Management of cornual pregnancy includes medical or surgical management. Early diagnosis allows conservative treatment with methotrexate; if it is made later in gestation, surgical treatment can be required. ${ }^{8}$ Recent studies have reported that a pharmacologically approach using methotrexate is usually effective, although there is insufficient evidence to recommend local or systemic approach. Major institution recommends that methotrexate should be the first line management for hemodynamically stable women with no pain, those with an unruptured ectopic pregnancy, a mass smaller than $35 \mathrm{~mm}$ with no visible heartbeat, and a serum b-hCG between 1500 and $5000 \mathrm{mIU} / \mathrm{ml}^{9}{ }^{9}$

Surgical treatment consists of conservative's techniques, such as laparoscopic or laparotomic cornual resection or cornuostomy or hysteroscopic removal of interstitial ectopic tissue, and radical operations such as salpingectomy or hysterectomy. ${ }^{10}$

Uterine rupture can occur after cornual (interstitial) pregnancy which is treated surgically as well as medically, and this is may occur in any trimester. ${ }^{11}$ Caesrean section is the optimum mode of delivery for subsequent pregnancies following cornual pregnancy to avoid the risk of intrapartum uterine rupture. ${ }^{12}$

\section{CONCLUSION}

Cornual pregnancy poses significant diagnostic and therapeutic challenge; early diagnosis may help to select the proper management and treatment according to the clinical presentation, hemodynamic stability, serum bhCG level and ultrasound findings. Early diagnosis and management remain the mainstay for tackling maternal mortality due to cornual pregnancy. In addition, counseling plays an important role in terms of risk during future pregnancies. The present report showed early diagnosis and management of the case of the unruptured right cornual pregnancy. Right cornuostomy via 
laparotomy was done in present case without any immediate or delayed complication.

Funding: No funding sources

Conflict of interest: None declared

Ethical approval: Not required

\section{REFERENCES}

1. Dagar M, Srivastava M, Ganguli I, Bhardwaj P, Sharma N, Chawla D. Interstitial and cornual ectopic pregnancy: conservative, surgical and medical management. J Obstet Gynaecol. 2018;68:471-6.

2. Stem E, Chanda M, Thorne J. Rupturing cornual pregnancy diagnosed at laparoscopy. J Obstet Gynaecol. 2019;41:265.

3. Shetty M, Shivananjaih C, Swarup A, Sharma N, Sharma N. A rare case report of cornual pregnancy. Obstet Gynaecol Int J. 2016;5:1-3.

4. Rock JA, Damario MA. Ectopic pregnancy. In: Thompson JD, Rock JA, eds. Te Linde's operative gynaecology. $8^{\text {th }}$ edition. Philadelphia: LipincottRaven. 1997:502-27.

5. Tulandi T, AI-Jaroudi D. Interstitial pregnancy: Results generated from the society of reproductive surgeon's registry. Obstetr Gynaecol. 2004;103:4750 .
6. Akrivis $\mathrm{CH}$, Varras $\mathrm{M}$, Kyparos J, Demou A, Stefanaki $\mathrm{S}$ et al. Early ultrasonographic diagnosis of unruptured interstitial pregnancy: A case report and review of the literature. Clin Exp Obstet Gynaecol. 2003;30:60-4.

7. Rizk B, Abuzeid M, Rizk C, Owens S, LaFleur J et al. Ultrasound in reproductive medicine and infertility, Cambridge University Press, Cambridge USA. 2010;31:259-70.

8. Jermy K, Thomas J, Doo A, Bourne Y. The conservative management of interstitial pregnancy. Int J Obstetr Gynaecol. 2004;111:1283-8.

9. Elson CJ, Salim R, Potdar N, Chetty M, Ross JA, Kirk EJ. Diagnosis and management of ectopic pregnancy. Int J Obstetr Gynaecol. 2016;123:15-55.

10. Faraj R, Steel M. Management of cornual (interstitial) pregnancy. Obstetr Gynaecol. 2007;9:249-55.

11. Gonzales SK, Adair CD, Gist WE. Uterine rupture at term following a prior wedge resection for interstitial pregnancy. Austin J Obstet Gynaecol. 2015;2:1035.

12. Grimbizis GF, Tsalikis T, Mikos T. Case report: Laparoscopic treatment of a ruptured interstitial pregnancy. Reproductive Biomed Online. 2004;9:447-51.

Cite this article as: Bansal P, Aggarwal G, Bansal I. A rare case report of cornual pregnancy. Int J Reprod Contracept Obstet Gynecol 2021;10:3986-8. 